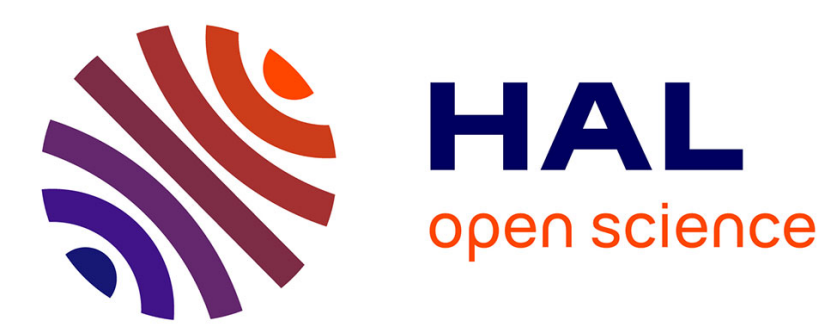

\title{
Interactions between kaolinite and phosphinate-based flame retardant in Polyamide 6
}

\author{
M A Batistella, Rodolphe Sonnier, B Otazaghine, C O Petter, J M \\ Lopez-Cuesta
}

\section{- To cite this version:}

M A Batistella, Rodolphe Sonnier, B Otazaghine, C O Petter, J M Lopez-Cuesta. Interactions between kaolinite and phosphinate-based flame retardant in Polyamide 6. Applied Clay Science, 2018, 157, pp.248-256. 10.1016/j.clay.2018.02.021 . hal-02884619

\section{HAL Id: hal-02884619 \\ https://hal.science/hal-02884619}

Submitted on 26 May 2021

HAL is a multi-disciplinary open access archive for the deposit and dissemination of scientific research documents, whether they are published or not. The documents may come from teaching and research institutions in France or abroad, or from public or private research centers.
L'archive ouverte pluridisciplinaire HAL, est destinée au dépôt et à la diffusion de documents scientifiques de niveau recherche, publiés ou non, émanant des établissements d'enseignement et de recherche français ou étrangers, des laboratoires publics ou privés. 


\title{
Interactions between kaolinite and phosphinate-based flame retardant in Polyamide 6
}

\author{
Batistella M.A. ${ }^{\text {a,*, }}$, Sonnier R. ${ }^{\mathrm{b}}$, Otazaghine B. ${ }^{\mathrm{b}}$, Petter C.O. ${ }^{\mathrm{c}}$, Lopez-Cuesta J.-M. ${ }^{\mathrm{b}}$ \\ ${ }^{\text {a }}$ Federal University of Santa Catarina, R. Eng. Agronômico Andrei Cristian Ferreira, s/n - Trindade, Florianópolis, SC CEP 88040-900, Brazil \\ ${ }^{\mathrm{b}}$ Ecole des Mines d'Alès, Centre des Matériaux (C2MA) - Pôle Matériaux Polymères Avancés, 6 Avenue de Clavières, 30319 Alès, Cedex, France \\ ${ }^{\mathrm{c}}$ Federal University of Rio Grande do Sul, Av. Bento Gonçalves, 9500, Porto Alegre CEP 91501-970, Brazil
}

\section{A B S T R A C T}

The interactions between kaolinite and a commercially available phosphinate-based flame retardant (Exolit ${ }^{\circledR}$ OP1311) were evaluated as flame retardant systems in Polyamide 6 (PA6). The thermal degradation and flammability of PA6 composites were studied by TGA and cone calorimeter tests. Characterizations were conducted using FTIR, EDX and XRD. Cone calorimeter results showed a reduction in peak heat release rate (pHRR) as a function of filler loading and type with a greater reduction for OP1311 containing composites. Interestingly, OP1311 can be partially substituted by kaolinite without detrimental effect on peak of release rate (pHRR) measured by cone calorimeter. FTIR, EDX and XRD analysis of cone calorimeter residues showed that kaolinite may trap some phosphorous compounds in condensed phase leading to the formation of a glassy structure on sample residue. To assess possible interactions between kaolinite and phosphinate, a controlled thermal degradation was carried out on kaolinite, OP1311 and kaolinite/OP1311 (50:50) blends. The residues were analyzed by EDX and XRD. Results showed that almost all phosphorous present in the initial sample remains in residue for Kaolinite/OP1311 blend versus only about $60 \%$ for OP1311 alone. Also, XRD results showed that during combustion, new crystalline phases can be formed in the sample when kaolinite is combined with OP1311. These results suggest that some interactions between both components may occur and could explain the observed fire behavior of the composites containing kaolinite and phosphinate.

\section{Introduction}

Polyamide 6 (PA6) is an important engineering polymer for electrical and electronic applications when flame retardancy is a major concern. Since it is quite often necessary to add flame retardant agents, they act, depending on their nature, chemically and/or physically in the solid or gaseous phase during the different stages of combustion. Hence, various flame retardant systems were proposed to improve polyamide fire retardancy, in particular nanoparticles (Pramoda et al., 2003; Samyn and Bourbigot, 2012; Weil and Levchik, 2004), mineral fillers (Batistella et al., 2015; Clerc et al., 2005) and phosphorous compounds (Braun et al., 2007; Braun and Schartel, 2004; Levchik et al., 1996a,b,c; Samyn and Bourbigot, 2012). Different mineral fillers at micronic and nanometric scale have attracted attention since they can impart advantageous mechanical (Batistella et al., 2015; Chow et al., 2003; Norris, 1990) and barrier properties (Alexandre and Dubois, 2000; Cabedo et al., 2004) as well as fire behavior (Beyer, 2006; Braun et al., 2007; Clerc et al., 2005; Vahabi et al., 2012). Generally, the addition of these mineral fillers reduces the total amount of fuel and the rate of diffusion of oxygen into the polymer. Also, the mineral fillers may accumulate on the surface of the decomposing polymer, shielding it from incoming radiation. Moreover, the addition of mineral fillers in the polymers can significantly change their combustion and thermal degradation pathway. The presence of these fillers will affect certain properties such as the heat capacity and the thermal conductivity of the material. Various mineral fillers received particular attention in literature such as hydrated mineral fillers and clay minerals. Hydrated fillers decompose at high temperature through endothermic release of water, slowing down the heating of the material. Considering the use of natural mineral-based nanoparticles, the use of clay minerals as components of flame retardant systems is being increasingly studied and many works have dealt with the use of organomodified montmorillonites (o-Mt) (Ramani et al., 2010; Sanchez-Olivares et al., 2008; Zhang et al., 2008), talcs (Clerc et al., 2005; Durin-France et al., 2000; Leong et al., 2004), halloysites (Hedicke-Höchstötter et al., 2009), sepiolites (Huang, 2010; Laoutid et al., 2013) or kaolinites (Batistella et al., 2016, 2014) as flame retardants.

\footnotetext{
* Corresponding author.

E-mail address: marcos.batistella@posgrad.ufsc.br (M.A. Batistella).
} 
Generally speaking, the use of clay minerals alone is not enough to achieve acceptable levels of fire retardancy. Therefore, different compositions containing mineral fillers and phosphorous compounds were found to be efficient to reduce the heat release rate due to the formation of a protective surface barrier (Samyn and Bourbigot, 2012; Vahabi et al., 2013; Weil and Levchik, 2004). Consequently, efforts have been done to study the influence of phosphorous based additives in polyamide 6 and possibly synergies between phosphorous and mineral fillers (Braun et al., 2007; Braun et al., 2006; Levchik et al., 1996a,b,c). Inorganic and organic phosphorous compounds are extensively used to improve the fire behavior of many polymers. The range of phosphorous products is extremely broad and includes compounds of varied structure: phosphates, phosphonates, phosphinates and red phosphorus. The modes-of-action of these phosphorous compounds include flame inhibition in gas phase and char formation in condensed phase. The formation of a char layer during the fire test may protect the material and acts as a barrier to oxygen and heat of the flame. The flame retardant mechanism of the phosphorous compounds will depend on the type of compound used and the chemical structure of the polymer matrix to be flame retarded. The use of phosphinates has increased in the last years. Their beneficial impact on the fire performances has been studied either when used alone or in synergism with other components in various compounds as glass fibers reinforced polyamide 6 and 6,6 (Braun et al., 2007; Schartel et al., 2003), poly(methyl methacrylate) (Laachachi et al., 2007), poly (ethylene terephthalate) (Alongi, 2011), among others. Zhan et al. studied the synergistic effects of sepiolite and aluminum diethylphosphinate (AlPi) in PA66 (Zhan et al., 2015). Authors showed that the addition of $0.3 \mathrm{wt} \%$ of sepiolite allows reducing the amount of AlPi while maintaining a V-0 rating on UL-94 test and the same reduction in pHRR. Also, authors analyzed the char residues and showed that the incorporation of sepiolite changed the degradation process of the PA66/AlPi system and possibly formed diethylphosphinic acid, silicon-phosphate and magnesium-phosphate products in condensed phase, which enhanced the thermal stability and char yield of PA66 materials at high temperature.

Ramani et al. also studied synergistic effects of organomodified montmorillonite (Cloisite 30B) and OP1311 in PA6 by thermogravimetric analysis (TGA) and differential scanning calorimetry (DSC) (Ramani and Dahoe, 2014). In their study, the weight of final residue of o-Mt and OP1311 containing composites was higher compared to a simple mixture rule of additives. Using TGA coupled with FTIR analyses, the authors showed that, at higher temperatures (above $400{ }^{\circ} \mathrm{C}$ ), a water release is produced by the degradation of hydroxyl groups of the clay mineral layers, leading to a collapse of the crystal structure of melamine polyphosphate and the formation of an amorphous phase composed of metal oxides. Samyn et al. studied interactions between aluminum phosphinate, melamine polyphosphate and o-Mt in PA6 and PA66 (Samyn and Bourbigot, 2012). Authors showed that, under nitrogen, the presence of o-Mt decreases the initial decomposition temperature of aluminum phosphinate/melamine polyphosphate but the decomposition products are the same indicating that no interaction takes place between the additives. However, under air, the combined action of o-Mt and oxygen converts all the phosphinates into aluminophosphate species which contribute to an improvement in fire behavior measured by cone calorimeter for PA66 composites.

Braun et al. studied the effect of addition of a zinc borate in combination with aluminum phosphinate and melamine polyphosphate in glass fiber reinforced PA66 (Braun et al., 2007). The authors showed that the reactivity of the phosphorous additive with the polymer matrix influences not only the gas or condensed phase, but also the interaction with other additives. Also, the authors showed that the main flameinhibition effect of the phosphinates in glass fiber PA66 is replaced by a strong barrier effect when the zinc borate is added to the formulation with a reduction in the flame inhibition effect.

Other layered silicates than o-Mt, which can be combined with phosphorous FRs, like kaolinite, have received less attention. Kaolinite is an aluminosilicate with theoretical formula $\mathrm{Al}_{2} \mathrm{Si}_{2} \mathrm{O}_{5}(\mathrm{OH})_{4}$ and basal interlayer space of $7.1 \AA$. Kaolinite is a $1: 1$ or tetrahedral/octahedral (TO) type clay mineral, since it is formed by combining clay mineral layers of Si tetrahedra (T) and Al octahedra (O), in 1:1 proportion. The layers remain attached to each other because they share common oxygen atoms, giving rise to the structure of the clay mineral (Brindley, 1986; Giese Jr. and Giese, 1973). In a previous work, our group studied the influence of surface treatment of kaolinite in mechanical and fire properties of PA6 compounds. It was shown that surface treatment leads to different microstructures that influence fire properties measured by cone calorimeter. Kaolinite with surface modified with (3glycidoxypropyl)trimetoxysilane decreased pHRR by about $70 \%$ compared to neat polymer and about $40 \%$ compared to PA6 filled with untreated kaolinite (Batistella et al., 2015).

Therefore, in this study, the effect of incorporation of kaolinite and a phosphinate-based flame retardant (Exolit ${ }^{\oplus}$ OP1311) on the fire reaction of PA6 is studied and interactions between components were evaluated in order to understand the mechanisms of fire retardancy and to establish possible synergistic effects.

\section{Materials and methods}

Commercial polyamide (PA6, Technyl ${ }^{\circledR}$ C206-Rhodia), phosphinatebased flame retardant (Exolit ${ }^{\circledR}$ OP1311-Clariant) and kaolinite (Paralux - Vale with a mean diameter of $0.8 \mu \mathrm{m}$ and a surface specific area of $12.2 \mathrm{~m}^{2} \cdot \mathrm{g}^{-1}$ measured by B.E.T.) were used as received. Characteristic dimensions of kaolinite layers are showed in Fig. 1. Prior to compounding, neat PA6 and PA6 composites were dried under vacuum at $80^{\circ} \mathrm{C}$. Previous studies showed that OP1311 is an aluminum diethylphosphinate enriched with nitrogenous compounds such as melamine polyphosphate, acting as synergistic agents. The elementary analysis showed that phosphorus is about $20 \mathrm{wt} \%$ and nitrogen about $14 \mathrm{wt} \%$ (Laachachi et al., 2007).

\subsection{Compounds preparation}

Blends of fillers and polymers were prepared by melt compounding in a twin screw extruder (Clextral, Firminy-France). The rotation speed was kept at $150 \mathrm{rpm}$, temperature ranged between 200 and $240{ }^{\circ} \mathrm{C}$ and polymer output was $4.5 \mathrm{~kg} / \mathrm{h}$. Square sheets specimens were prepared with dimensions of $100 \times 100 \times 4 \mathrm{~mm}^{3}$ by injection molding using a 50 ton Krauss-Maffei equipment (Munich, Germany) and temperature range from 200 to $260{ }^{\circ} \mathrm{C}$. The formulations are showed in Table 1 .

\subsection{Characterization}

XRD patterns were obtained using a Bruker AXS D8 Advance diffractometer with $\mathrm{CuK} \alpha$ radiation and a Vantec detector. The scanning

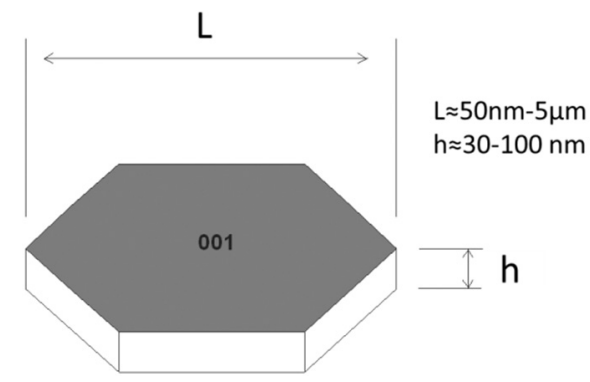

Fig. 1. Characteristic dimensions of kaolinite used in this study. 
Table 1

Formulations studied.

\begin{tabular}{llll}
\hline Sample & PA6 (wt\%) & Kaolinite (wt\%) & OP1311 (wt\%) \\
\hline PA & 100 & - & - \\
PA-Kaol-10 & 90 & 10 & - \\
PA-Kaol-20 & 80 & 20 & - \\
PA-OP-10 & 90 & - & 10 \\
PA-OP-20 & 80 & - & 20 \\
PA-Kaol-10/OP-10 & 80 & 10 & 10 \\
\hline
\end{tabular}

range was from $5^{\circ}$ to $30^{\circ}$ with a step size of $0.007^{\circ}$. TGA measurements were carried out in a Perkin-Elmer Pyris-1 TGA under air or nitrogen $\left(20 \mathrm{ml} \cdot \mathrm{min}^{-1}\right)$ from 50 to $800{ }^{\circ} \mathrm{C}$ at $10^{\circ} \mathrm{C} \cdot \mathrm{min}^{-1}$ on a $10 \pm 2 \mathrm{mg}$ sample. FTIR analyses were conducted in a Bruker IF66 equipment from 4000 to $400 \mathrm{~cm}^{-1}$ using a resolution of $4 \mathrm{~cm}^{-1}$. $\mathrm{KBr}$ pellets were prepared using 2 to $4 \mathrm{mg}$ of sample with $200 \mathrm{mg}$ of $\mathrm{KBr}$. The samples were observed using a FEI Quanta 200 scanning electron microscope and their elemental compositions were determined by Energy Dispersive Xray spectroscopy (EDX) using Oxford INCA Energy 300 system and a detector of $133 \mathrm{eV}$ (at $\mathrm{Mn}$ ).

Cone calorimeter tests were carried out in an FTT apparatus according to ISO 5660-1 using an external heat flux of $50 \mathrm{~kW} \cdot \mathrm{m}^{-2}$. Three samples were tested and mean values were reported. Pyrolysis Combustion Flow Calorimeter (PCFC) analysis was carried out according to the method A (anaerobic pyrolysis) of the ASTM D7309 using a FTT apparatus with a heating rate of $1{ }^{\circ} \mathrm{C} \cdot \mathrm{s}^{-1}$, the maximum pyrolysis temperature was $750{ }^{\circ} \mathrm{C}$ and the combustion temperature was $900{ }^{\circ} \mathrm{C}$ (corresponding to complete combustion). The flow in combustor was a mixture of $\mathrm{O}_{2} / \mathrm{N}_{2} 20 / 80$ at $100 \mathrm{~cm}^{3} \cdot \mathrm{min}^{-1}$ and the sample weight was $2 \pm 0.5 \mathrm{mg}$.

According to the TGA curves of the composites, four temperatures characteristic of the different steps of decomposition have been chosen (350, 450, 600 and $800{ }^{\circ} \mathrm{C}$ ). Thermal treatments have been carried out at these temperatures in order to simulate the decomposition process and to investigate the chemical species formed in the condensed phase at these different steps. For these treatments, about $10 \mathrm{~g}$ of the sample were put in a furnace with an increase of $30^{\circ} \mathrm{C} / \mathrm{min}$ up to the defined temperature $\left(350,450,600\right.$ or $800{ }^{\circ} \mathrm{C}$ ) and underwent the thermal degradation for $2 \mathrm{~h}$ under air. After thermal treatment, these samples were kept in a desiccator in vacuum until further analyses.

\section{Results and discussion}

\subsection{Thermal degradation of PA6 composites}

Various studies of Levchik (Levchik et al., 1999) focused on the thermal degradation of polyamide 6. Many thermal degradation products were identified and it was noticed that their quantity and nature
Table 2

Caracterisitc temperatures under $\mathrm{N}_{2}$ and air.

\begin{tabular}{lllllll}
\hline Sample & $\begin{array}{l}\mathrm{T} \text { onset } \\
\mathrm{N}_{2}\left({ }^{\circ} \mathrm{C}\right)\end{array}$ & $\begin{array}{l}\mathrm{T} \text { peak } \\
\mathrm{N}_{2}\left({ }^{\circ} \mathrm{C}\right)\end{array}$ & $\begin{array}{l}\text { Mass } \\
\text { residue } \mathrm{N}_{2} \\
(\%)\end{array}$ & $\begin{array}{l}\mathrm{T} \text { onset } \\
\text { air }\left({ }^{\circ} \mathrm{C}\right)\end{array}$ & $\begin{array}{l}\mathrm{T} \text { peak } \\
\text { air }\left({ }^{\circ} \mathrm{C}\right)\end{array}$ & $\begin{array}{l}\text { Mass } \\
\text { residue } \\
\text { air (\%) }\end{array}$ \\
\hline PA & 348 & 463 & - & 357 & 456 & - \\
PA-Kaol-10 & 341 & 461 & 9 & 369 & 464 & 9.3 \\
PA-Kaol-20 & 348 & 463 & 17.6 & 374 & 477 & 16.1 \\
PA-OP-10 & 300 & 459 & 2.7 & 284 & 455 & 2.3 \\
PA-OP-20 & 294 & 458 & 6.2 & 286 & 457 & 4.1 \\
PA-Kaol-10/OP-10 & 308 & 470 & 11 & 303 & 468 & 10.1 \\
\hline
\end{tabular}

depend on the environment during the test (air or nitrogen). Mass loss obtained by TGA for polyamide 6 in oxidant and non-oxidant atmosphere is plotted in Fig. 2 and compared to PA-Kaol-20, PA-OP-20 and PA-Kaol-10/OP-10. In addition, complete results are presented in Table 2. Thermal degradation of neat polymer takes place in the range $330-490{ }^{\circ} \mathrm{C}$ in two steps with a maximum rate at $\approx 460{ }^{\circ} \mathrm{C}$ under nitrogen or air and a shoulder at $\approx 600^{\circ} \mathrm{C}$, which is ascribed to the degradation of a charred structure formed at lower temperatures. The incorporation of kaolinite leads to a different behavior depending on the atmosphere. Under nitrogen, a slight reduction in onset temperature is observed, depending on filler loading. However, temperature of peak does not change significantly compared to neat polymer. Also, the quantity of residue at $750{ }^{\circ} \mathrm{C}$ corresponds to the amount of filler added with no char formation (confirming cone calorimeter results, see infra). Moreover, under air, the addition of kaolinite leads to an increase both in onset and peak temperature of about $15-20^{\circ} \mathrm{C}$ depending on filler loading.

In the presence of OP1311, the thermal decomposition starts at lower temperature. The decomposition of PA-OP-20 starts at a temperature about $50^{\circ} \mathrm{C}$ under nitrogen and about $70^{\circ} \mathrm{C}$ lower under air than for pure polymer and the mass loss takes place in three steps, in agreement with the literature (Braun et al., 2007; Samyn and Bourbigot, 2012). Aluminum phosphinate (which is one of the components of OP1311 (Laachachi et al., 2007; Samyn and Bourbigot, 2012)) releases polyphosphoric acid, which reacts with PA6 producing phosphoric esters and primary amide chain ends (Levchik et al., 1996a,b,c).

Decomposition of PA-Kaol-10/OP-10 also takes place in three steeps and starts at lower temperature than neat polymer, due to the presence of OP1311. Comparing experimental and theoretical curves of the ternary blend, a slight increase in onset temperature under air was observed for experimental data, indicating that some interactions between additives or between additives and polymer could occur. The residue at $750{ }^{\circ} \mathrm{C}$ is about $11 \%$, slightly greater than mixture rule.
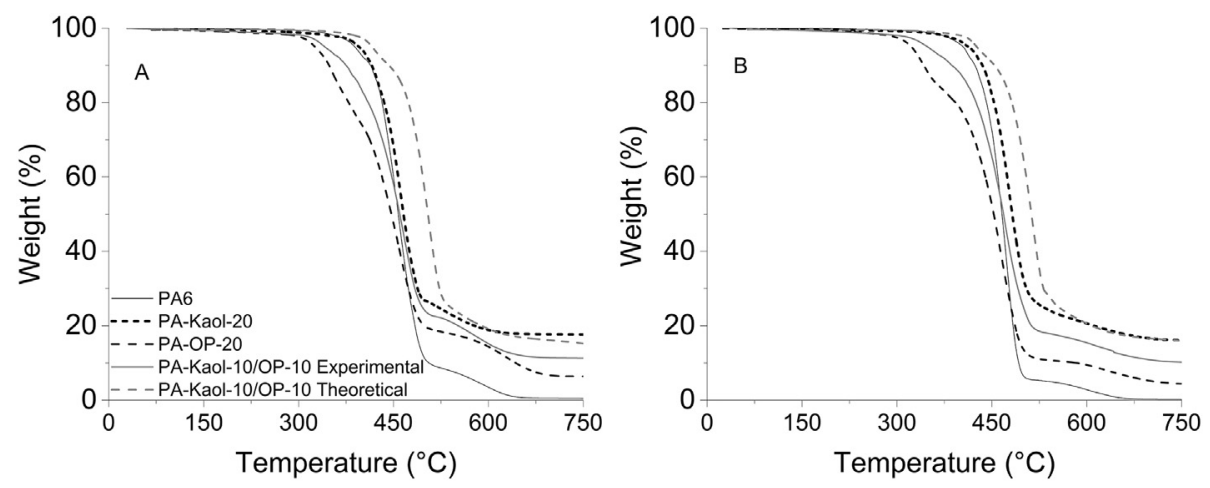

Fig. 2. TGA of Polyamide 6, PA-Kaol-20 PA-OP-20 and PA-Kaol-10/OP-1-10 composites under nitrogen (A) and air (B) at $10{ }^{\circ} \mathrm{C} \cdot \mathrm{min}^{-1}$. 


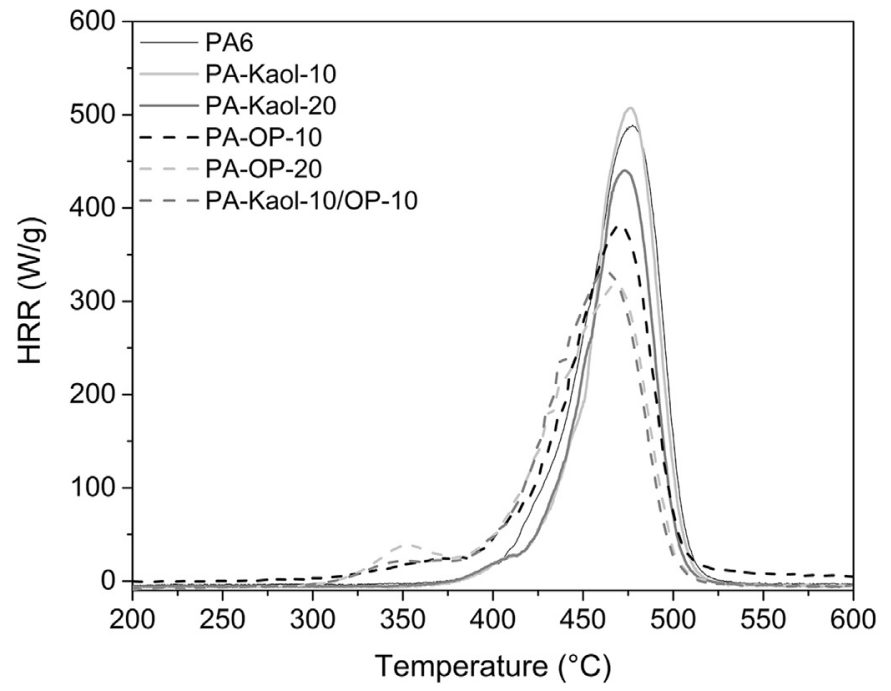

Fig. 3. PCFC results of composites.

\subsection{Pyrolysis combustion Flow Calorimeter tests}

Pyrolysis combustion flow calorimeter (PCFC) has been used to study the fire behavior of mg-sized samples (Lyon et al., 2007; Lyon and Walters, 2004; Schartel et al., 2007; Sonnier et al., 2011). The PCFC results are presented in Fig. 3. A decrease of HRC for both additives is observed, being slightly greater for OP composites. It is well accepted that mineral fillers impart an improvement in fire behavior by a surface protective layer which insulates the polymer and decreases mass transfer to gas phase and heat transfer to condensed phase. For PCFC analysis, this effect plays a negligible role since physical effects are not taken into account. In the case of kaolinite containing composites, for PA-Kaol-10 a slightly greater value of pHRR was observed which indicates that kaolinite could catalyze thermal degradation of PA6. As expected, in the case of OP containing composites, a greater reduction in pHRR was observed. Moreover a first small peak is observed at low temperature (about $350^{\circ} \mathrm{C}$ ) confirming the lower thermal stability of composites containing OP1311, in agreement with TGA analysis. In the case of PA-Kaol-10/OP-10, a further decrease was observed compared to composite containing only OP indicating that some interactions between filler and additives may occur.

\subsection{Cone calorimeter}

Heat release rate (HRR) plots of neat PA6 and composites filled with kaolinite, OP1311 and both additives are shown in Fig. 4 and complete results are presented in Table 3. The incorporation of kaolinite leads to a reduction in pHRR as a function of filler loading. For $10 \mathrm{wt} \%$ only a small reduction was observed, whereas for $20 \mathrm{wt}$ $\%$ a reduction of about $50 \%$ was achieved. In the case of OP1311,

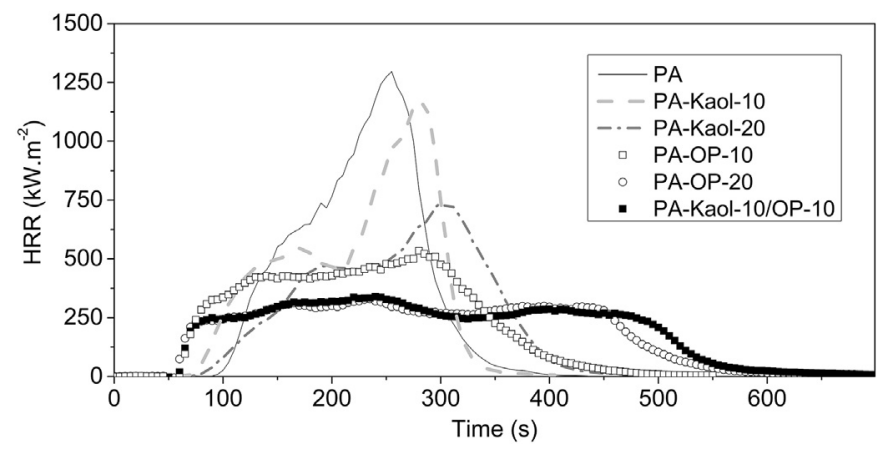

Fig. 4. HRR plots of the composites. Irradiance: $50 \mathrm{~kW} \cdot \mathrm{m}^{-2}$.
Table 3

Cone calorimeter results of PA6/Kaolinite and PA6/OP1311 composites.

\begin{tabular}{lllllll}
\hline Sample & $\begin{array}{l}\mathrm{pHRR} \\
\left(\mathrm{kW} / \mathrm{m}^{2}\right)\end{array}$ & TTI (s) & $\begin{array}{l}\text { THR } \\
\left(\mathrm{MJ} / \mathrm{m}^{2}\right)\end{array}$ & $\begin{array}{l}\text { EHC } \\
(\mathrm{kJ} / \mathrm{g})\end{array}$ & $\begin{array}{l}\text { TSR } \\
\left(\mathrm{m}^{2} /\right. \\
\left.\mathrm{m}^{2}\right)\end{array}$ & $\begin{array}{l}\text { Mass residue } \\
(\%)\end{array}$ \\
\hline PA & 1352 & 79 & 150 & 28.4 & 455 & 0 \\
PA-Kaol-10 & 1163 & 58 & 140 & 27.1 & 708 & 9 \\
PA-Kaol-20 & 779 & 70 & 126 & 26.1 & 965 & 18.7 \\
PA-OP-10 & 551 & 49 & 128 & 25.5 & 1470 & 2.6 \\
PA-OP-20 & 320 & 45 & 124 & 23.5 & 2600 & 5.4 \\
$\begin{array}{c}\text { PA-Kaol-10/ } \\
\text { OP-10 }\end{array}$ & 348 & 48 & 128 & 24.1 & 2300 & 11.4 \\
\hline
\end{tabular}

reductions of about $60 \%$ for PA-OP- 10 and about $80 \%$ for PA-OP-20 were observed in agreement with literature (Ramani and Dahoe, 2014; Samyn and Bourbigot, 2012). The ternary blend (PA-Kaol-10/ OP-10) showed the same behavior of PA-OP-20, with a reduction of about $80 \%$ in pHRR. For these two last composites, the curve shape is indicative of a thick charring behavior, i.e. an effective barrier effect (Schartel and Hull, 2007). Effective Heat of Combustion (EHC) of composites shows different behavior in function of additive type (Table 2). In the case of PA-Kaol-10 and PA-Kaol-20, a very limited decrease of EHC was observed which is consistent with a main action in condensed phase. As kaolinite releases only $14 \%$ of its weight as water vapor, it is reasonable to assume that the main action is the formation of a surface protective layer which decreases the mass transfer from condensed to gas phase and the heat transfer from the flame to underlying polymer (Batistella et al., 2016, 2014). In the case of PA-OP-10 and PA-OP-20, a greater decrease of EHC and an increase in char residue were observed, indicating that OP1311 acts both in condensed and gas phase. Braun et al. have shown that aluminum phosphinate in polyamide acts as flame inhibitor and releases phosphoric acid which can promote the formation of a char (Braun et al., 2007). Also, melamine polyphosphate releases ammonia, which acts in gaseous phase leading to a dilution of volatiles and to a reduction in EHC.

Time to ignition (TTI) of composites showed a different behavior. For composite containing kaolinite, the observed decrease in comparison to pristine polymer may be assigned to an increase of heat absorption on the sample surface (Delichatsios and Zhang, 2012; Fina et al., 2013). Another explanation proposed in the literature for the decrease of TTI for composites containing mineral fillers is the increase of the viscosity of the molten polymer (Kashiwagi et al., 2008). However, the incorporation of $20 \mathrm{wt} \%$ of kaolinite leads to an increase in TTI compared to PA-Kaol-10, possibly because the particles slow down the release of the volatiles and thus prevent the critical ignition concentration from being reached.

TTI of PA-OP composites showed a greater reduction compared to neat polymer. Levchik et al. have shown that melamine facilitates thermal degradation of PA6 interfering with the network of hydrogen bonds which leads to a decrease in TTI (Levchik et al., 1997). For the composite containing the mixture of kaolinite and OP1311, a decrease was also observed, possibly due to a combination of kaolinite in surface sample and the specific effect of OP311 which facilitates thermal degradation of PA6. All these results are in agreement with TGA, where a decrease in onset temperature was observed for the composites containing OP1311.

TSR values increased as a function of filler loading and filler type. It's accepted that carbon monoxide and smoke production correspond to incomplete combustion. In the present study, the smoke production is several times higher than that of neat PA6 as function of filler type and loading, in agreement with some results in literature (Braun et al., 2007, 2006). Also, the lower EHC and higher smoke production indicate that unburnt gases are present in gas phase. Braun et al. had studied the influence of addition of 
aluminum diethylphosphinate in glass fiber reinforced poly(1,4butylene terephthalate) and showed that the release of phosphinate compounds was observed in the gas phase of the flame retarded composites (Braun et al., 2008). They also reported that a strong increase in TSR (by a factor more than two) could be caused by a suppressed total oxidation process indicating a radical trapping mechanism (Braun et al., 2008).

The behavior and the visual appearance of composites under cone calorimeter test were also different from the neat polymer. For the PA-Kaol-20 sample, small bubbles burst at the surface of the sample during the cone calorimeter test, followed by the ignition. After $100 \mathrm{~s}$, the surface was covered by large bursting bubbles with vigorous bubbling and a low viscous behavior. At the end of the test, a thin, grey and non-cohesive residue was observed. The residue content corresponds only to mineral residue from kaolinite decomposition.

The incorporation of 10 or $20 \mathrm{wt} \%$ of OP1311 (PA-OP-20) leads to a different behavior. Before ignition, small bubbles burst at the surface of the sample, followed by ignition. After $100 \mathrm{~s}$, sample surface was covered with a thin char layer. At the end of the test, a thin, black residue was found.

For PA-Kaol-10/OP-10, in the pre-ignition period a black, protective and cohesive layer was observed which remained until the end of the test. It seems that the combination of kaolinite with OP1311 limits bubbling and mass transfer from the pyrolysis front to the flame. Moreover the formation of a slightly rigid layer allows limiting heat transfer from the flame to the underlying material. This barrier effect is well documented in literature for various nanocomposites systems, reducing the mass loss rate and the HRR values (Cárdenas et al., 2008; Durin-France et al., 2000; Kashiwagi et al., 2004; Samyn and Bourbigot, 2012).

The reduction in pHRR for all composites observed in cone calorimeter test is less marked compared to PCFC results. Since it is known that PCFC test does not take into account physical effects like barrier effect, this one can be observed only for relatively thick samples, but not for 2-5 mg-scale sample (Schartel et al., 2007; Sonnier et al., 2011). Using this assumption, we proposed in a previous study (Sonnier et al., 2011) a new method to evaluate the barrier effect by comparing the results of cone and PCFC tests. In this method, two parameters are calculated: the ratio $\mathrm{R}_{1}$ between pHRR of the composite and of the neat polymer obtained by PCFC and the ratio $R_{2}$ between pHRR of the composite and of the neat polymer obtained by cone calorimeter. Then $R_{1}$ is plotted according to $R_{2}$ for different wt $\%$ of mineral filler. The gap between the plotted points and the curve $\mathrm{X}=\mathrm{Y}$ depends on the barrier effect. Indeed an important shift $\left(R_{1}>>R_{2}\right)$ corresponds to an effective barrier effect.

$$
\begin{aligned}
& \left.R_{1}=\frac{p H R R_{\text {composite }}}{p H R R_{P A 6}} \text { (cone calorimeter }\right) \\
& R_{2}=\frac{p H R R_{\text {composite }}}{p H R R_{P A 6}}(P C F C)
\end{aligned}
$$

Fig. 5 plots $R_{2}$ vs $R_{1}$ for the different samples. All composites are shifted from the straight line $\mathrm{X}=\mathrm{Y}$. This deviation confirms our hypothesis for kaolinite composites: the heat and/or gas barrier effect is an important mode-of-action for the improvement of flame retardancy. Furthermore, for the composite containing kaolinite and OP, it appears that its behavior is very close to this of the composite containing $20 \mathrm{wt}$

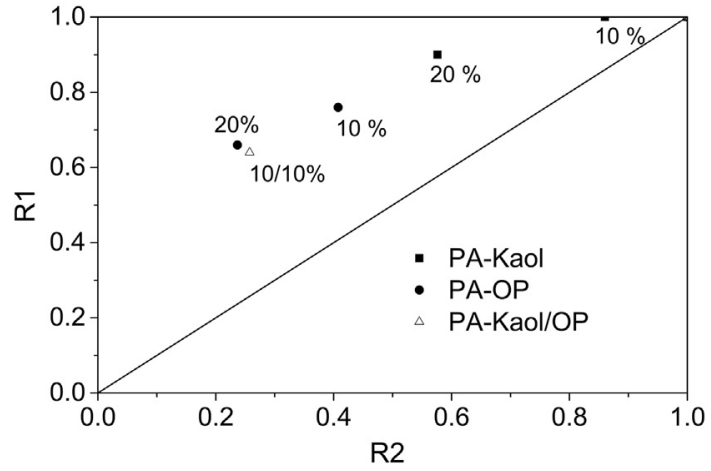

Fig. 5. R1 vs R2 plots for all studied composites.

$\%$ of OP (PA-OP-20). For PA-OP-10 and 20, the shift from the straight line is due both to barrier effect and flame inhibition. Indeed, combustion is complete in standard conditions in PCFC and flame inhibition does not occur.

On the whole, the fire performance of PA-Kaol-10/OP-10 and PAOP-20 seems very similar. In order to point out possible interactions with fillers and matrix, XRD, EDX and FTIR analysis were carried out on cone calorimeter residues.

\subsubsection{Analysis of cone calorimeter residues}

XRD spectra of cone calorimeter residues are presented in Fig. 6 . The spectra of the composites before the fire test show intense characteristic reflections of kaolinite and phosphinate (composites PA-Kaol and PA-OP). The spectrum of PA-Kaol-20 residue obtained after cone calorimeter test still exhibits the characteristic reflections of kaolinite (12 degrees (20)), with a lower intensity. Also, the formation of a poorly crystallized compound (shoulder reflection between 15 and 30 degrees

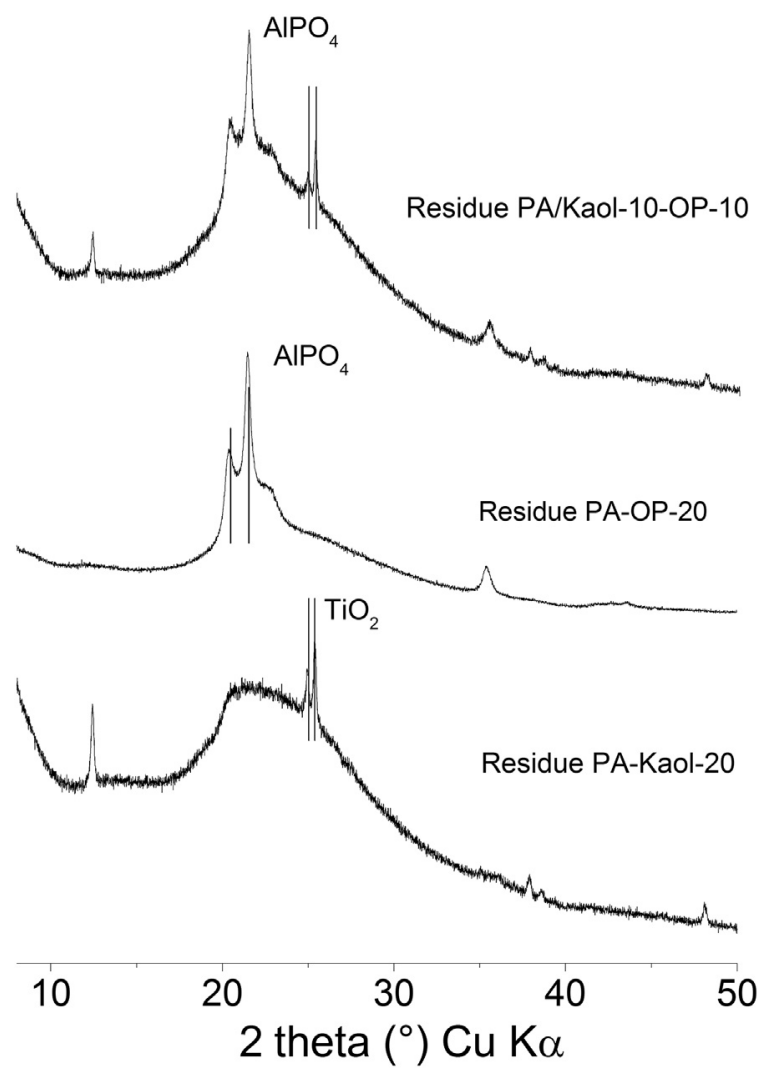

Fig. 6. XRD of cone calorimeter residues. 


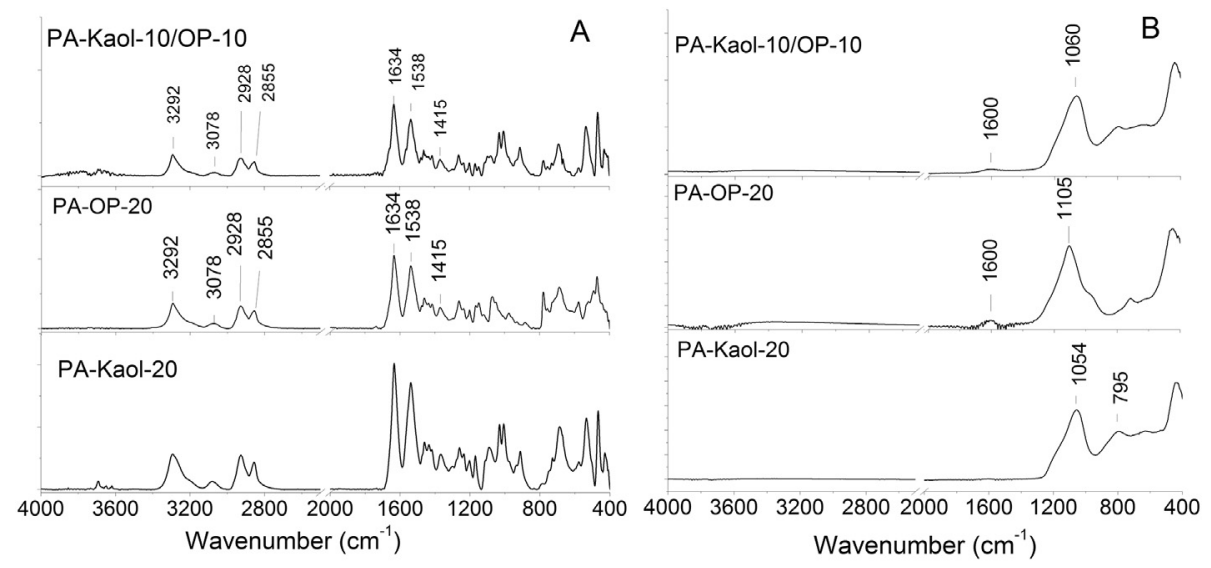

Fig. 7. FTIR of (A) composites and (B) cone calorimeter residues.

(20)) which may be attributed to the partial formation of metakaolinite is observed (Ptáček et al., 2014). PA-OP residue exhibits a crystalline phase which may be assigned to the formation of aluminophosphates $\left(\mathrm{AlPO}_{4}\right)$. The spectrum of the residue of the composite PA-Kaol-10/OP10 seems to be the sum of the spectra of PA-Kaol and PA-OP composites with the formation of a glassy phase (shoulder reflection between 20 and $30^{\circ}$ ) as observed in PA-Kaol-20 residue.

This result is also confirmed by the FTIR analyses on residues (Fig. 7). In the case of PA-Kaol residue it can be noted the absence of bands at $913 \mathrm{~cm}^{-1}$ (Al-OH) and in the region between 3700 and $3620 \mathrm{~cm}^{-1}$ corresponding to kaolinite hydroxyl groups which are present in the initial sample (Fig. 7A). The absence of bands at 539 and $913 \mathrm{~cm}^{-1}$ and the appearance of a new band at $800 \mathrm{~cm}^{-1}$ may be related to dehydroxylation of kaolinite (Ptáček et al., 2014). The band at $1054 \mathrm{~cm}^{-1}$ is attributed to the presence of amorphous silica which is present in kaolinite structure. The composite PA-OP has a band at $1600 \mathrm{~cm}^{-1}$ due to polyaromatic structures or CO bonds and a band at $1105 \mathrm{~cm}^{-1}$ assigned to aluminum phosphate products (aluminum polyphosphate, aluminum orthophosphate or aluminum pyrophosphate (Braun et al., 2007)).

Interestingly, comparing the ratio between initial and final phosphorus content (as showed in Table 4) and calculated as explained in Eq. (3), in the case of PA-OP-20 composite, near of $70 \mathrm{wt} \%$ of phosphorus content is released in gas phase indicating that in this case the mode of action may be flame inhibition. For PA-Kaol-10/OP-10, a slightly higher phosphorus content was observed. This result suggests that kaolinite may trap phosphorous compounds in condensed phase or some interaction between kaolinite and OP1311 may occur.

$$
P(\%)=\frac{P_{\text {initial }}-P_{\text {final }}}{P_{\text {Initial }}} \times 100
$$

Braun et al. analyzed the surface of residues obtained in cone calorimeter of glass fiber reinforced PA6 fire retarded with diethyl aluminum phosphate and melamine polyphosphate and showed that the surface is dominated by low carbon contents and high contents

Table 4

Percentage of initial phosphorus remaining in the residue measured using X-microanalysis (EDX).

\begin{tabular}{lll}
\hline Sample & P (\%) & N (\%) \\
\hline PA-Kaol-20 & 0 & 0 \\
PA-OP-20 & 29 & 3 \\
PA-Kaol-10/OP-10 & 35 & 8 \\
\hline
\end{tabular}

of heteroatoms (nitrogen, oxygen, phosphorus) with a higher nitrogen concentration for the composite containing flame retardants (Braun et al., 2007).

In order to assess the interactions that may occur between kaolinite and OP in cone calorimeter test, XRD, FTIR and EDX analysis of residues of Kaolinite/OP1311 blends were performed.

\subsection{Thermal analysis of kaolinite/phosphinate mixture}

TGA thermograms of kaolinite, OP1311 and a blend of Kaolinite/ OP1311 1:1 are presented in Fig. 8. Kaolinite degrades thermally in one step in agreement with the literature (Ptáček et al., 2014). Under nitrogen or air, kaolinite loses $14 \mathrm{wt} \%$ corresponding to dehydroxylation. OP1311 degrades in a three steps process. Between 350 and $410{ }^{\circ} \mathrm{C}$, a slow decomposition is observed with a maximum of the decomposition rate around $403{ }^{\circ} \mathrm{C}$ and corresponding to a loss of $5 \mathrm{wt} \%$. The second step occurs between 450 and $550{ }^{\circ} \mathrm{C}$ and corresponds to a mass loss of $73 \%$. Between 550 and $650{ }^{\circ} \mathrm{C}$, a last step of decomposition can be noticed, corresponding to a mass loss of $11 \%$ and leading to a stable residue of about $11 \mathrm{wt} \%$.

Comparing experimental and theoretical curves, the addition of kaolinite to OP leads to a slightly lower onset degradation temperature of OP (Fig. 8). The experimental and the theoretical curves of Kaol/OP are not superimposed, suggesting that interactions between $\mathrm{OP}$ and kaolinite occur and may lead to a destabilization of OP, even if the experimental and theoretical residues are similar. Moreover, temperature peak is shifted to lower values comparing theoretical and experimental data (from 468 to $450{ }^{\circ} \mathrm{C}$, respectively). According to the TGA curves of the compounds, four characteristic temperatures have been determined in air: $350,450,600$ and $800{ }^{\circ} \mathrm{C}$. Hence, thermal treatments have been carried out at these temperatures in order to simulate the decomposition process and to investigate the chemical species formed at these different temperatures. At the selected temperatures, the sample is heated in a furnace for $2 \mathrm{~h}$ with a ramp of $30^{\circ} \mathrm{C} \cdot \mathrm{min}^{-1}$. XRD, FTIR and EDX analysis were carried out to characterize the treated samples.

XRD patterns of kaolinite, OP and Kaol/OP (50/50) blend are presented in Fig. 9. Kaolinite is thermally stable until $450{ }^{\circ} \mathrm{C}$. At this temperature, it starts to decompose and loses its structural water. Therefore, as kaolinite contains traces of anatase, at $600{ }^{\circ} \mathrm{C}$, only anatase and an amorphous broad band due to the transformation of kaolinite to metakaolinite are observed. These results are in agreement with the literature (Paper et al., 2010).

From room temperature to $350{ }^{\circ} \mathrm{C}$, OP1311 presents partially crystalline structures characterized by the patterns displayed on Fig. 9. Between 350 and $450^{\circ} \mathrm{C}$, OP1311 degrades, resulting in the formation of an amorphous phase and remains amorphous until $800{ }^{\circ} \mathrm{C}$.

The diffractogram of Kaol/OP is slightly different from the simple 

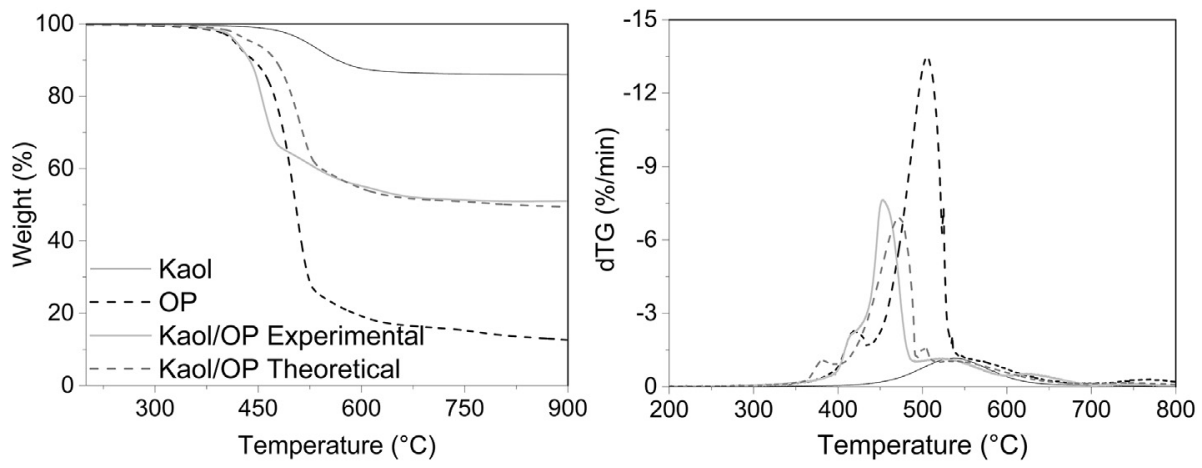

Fig. 8. TGA of Kaolinite, OP1311 and a 50:50 Kaol/OP blend at $10^{\circ} \mathrm{C} \cdot \mathrm{min}^{-1}$ under air.

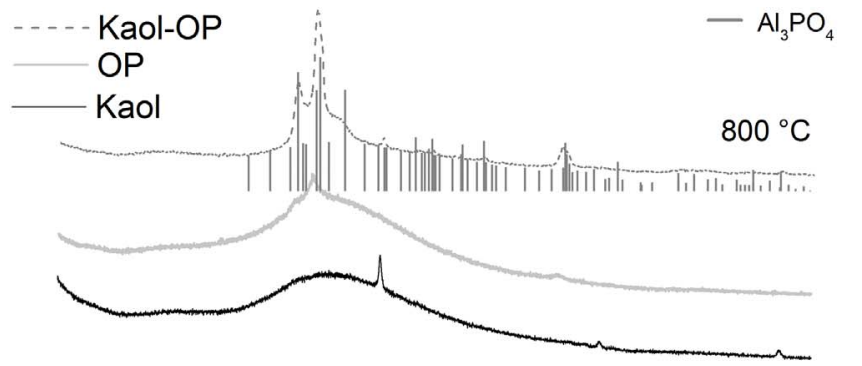

Table 5

Elementary analysis of $\mathrm{OP}$ and $\mathrm{Kaol} / \mathrm{OP}$ at 350 and $800^{\circ} \mathrm{C}$.

\begin{tabular}{lll}
\hline Element & OP & Kaol/OP \\
\hline $\mathrm{P}(\%)\left(350^{\circ} \mathrm{C}\right)$ & 98 & 98 \\
$\mathrm{~N}(\%)\left(350^{\circ} \mathrm{C}\right)$ & 26 & 49 \\
$\mathrm{P}(\%)\left(800^{\circ} \mathrm{C}\right)$ & 60 & 90 \\
$\mathrm{~N}(\%)\left(800^{\circ} \mathrm{C}\right)$ & 5.3 & 8.2 \\
\hline
\end{tabular}

phosphorus content changes according to the sample and the treatment temperature. It is interesting to note that the phosphorus content of Kaol/OP is much higher than for OP alone. This confirms that more phosphorus remains in condensed phase in presence of kaolinite indicating that the main mode of action of OP changes when associated with the clay mineral. OP acts mainly in the condensed phase when combining with kaolinite due to a synergistic effect. It should be noted that the residence time of phosphorus degradation products could be longer due to a barrier effect, leading to the formation of secondary species. It is also interesting to note that nitrogen content was different depending if $\mathrm{OP}$ is alone or in combination with kaolinite. At $350{ }^{\circ} \mathrm{C}$ a difference of about $20 \%$ in nitrogen was observed. At $800{ }^{\circ} \mathrm{C}$ a lower difference was observed. These results indicate that kaolinite could also partially trap nitrogen compounds, which could come from the degradation of melamine polyphosphate, possibly used as synergistic agent of phosphinate, from the thermal degradation of OP.

\section{Conclusions}

The influence of the incorporation of kaolinite and a phosphinate compound in PA6 matrix was evaluated in terms of fire retardancy. Also, the interactions between these additives during a fire test were analyzed. Cone calorimeter results showed that the addition of kaolinite leads to an improved fire performance for $20 \mathrm{wt} \%$ compared to neat polymer in terms of pHRR. As expected, the addition of OP leads to a better improvement in fire behavior observed in cone calorimeter. For kaolinite, only a condensed phase mode of action is observed as reported in literature, whereas OP1311 acts both in gas phase by flame inhibition as well as dilution of combustible gases (ammonia release) and in condensed phase by charring promotion thanks to phosphinate which may degrade into phosphoric acid.

The partial substitution of OP1311 by kaolinite is not detrimental for fire retardancy as observed by cone calorimeter. HRR curves are similar. Moreover, the presence of kaolinite changes the mode-of-action of OP due to interactions between both additives. Kaolinite may trap some phosphorus and nitrogen compounds, limiting the flame inhibition effect of OP and probably promotes the barrier effect protecting the polymer matrix from the radiant heat and slowing down the mass transfer from the gas phase.

Results of thermal degradation of these additives obtained in controlled conditions show that some interactions between kaolinite and 
OP occur at higher temperatures. XRD analysis shows the formation of alumino-phosphorous compounds at high temperature which are not observed for OP alone. Also, elementary analysis evidence that phosphorus content remaining in the residue is higher in the presence of kaolinite.

Nevertheless, analyses carried out on cone calorimeter residues do not show the formation of new phases. Only an increase in phosphorus content is observed in the case of composites containing kaolinite and OP compared to the composite containing only OP.

These results indicate that kaolinite changes the mode-of-action of OP1311 to a certain extent, by trapping phosphorous in condensed phase, and may replace partially OP1311 without affecting negatively fire behavior.

\section{References}

Cárdenas, M.A.A., García-López, D., Gobernado-Mitre, I., Merino, J.C.C., Pastor, J.M.M., Martínez, J.D.D., Barbeta, J., Calveras, D., 2008. Mechanical and fire retardant properties of EVA/clay/ATH nanocomposites - effect of particle size and surface treatment of ATH filler. Polym. Degrad. Stab. 93, 2032-2037. http://dx.doi.org/10. 1016/j.polymdegradstab. 2008.02.015.

Alexandre, M., Dubois, P., 2000. Polymer-layered silicate nanocomposites: preparation, properties and uses of a new class of materials. Mater. Sci. Eng. R Reports 28, 1-63. http://dx.doi.org/10.1016/S0927-796X(00)00012-7.

Alongi, J., 2011. Investigation on flame retardancy of poly(ethylene terephthalate) for plastics and textiles by combination of an organo-modified sepiolite and $\mathrm{Zn}$ phosphinate. Fibers Polym. 12, 166-173. http://dx.doi.org/10.1007/s12221-011-0166-5.

Batistella, M., Otazaghine, B., Sonnier, R., Caro-Bretelle, A.-S.S., Petter, C., Lopez-Cuesta, J.-M.M., 2014. Fire retardancy of ethylene vinyl acetate/ultrafine kaolinite composites. Polym. Degrad. Stab. 100, 54-62. http://dx.doi.org/10.1016/j. polymdegradstab. 2013.12.026.

Batistella, M., Caro-Bretelle, A.S., Otazaghine, B., Ienny, P., Sonnier, R., Petter, C., LopezCuesta, J.M., 2015. The influence of dispersion and distribution of ultrafine kaolinite in polyamide- 6 on the mechanical properties and fire retardancy. Appl. Clay Sci. 116-117, 8-15. http://dx.doi.org/10.1016/j.clay.2015.07.034.

Batistella, M., Otazaghine, B., Sonnier, R., Petter, C., Lopez-Cuesta, J.-M., 2016. Fire retardancy of polypropylene/kaolinite composites. Polym. Degrad. Stab. 129, 260-267. http://dx.doi.org/10.1016/j.polymdegradstab. 2016.05.003.

Beyer, G., 2006. Flame retardancy of nanocomposites based on organoclays and carbon nanotubes with aluminium trihydrate. Polym. Adv. Technol. 17, 218-225. http://dx. doi.org/10.1002/pat.696.

Braun, U., Schartel, B., 2004. Flame retardant mechanisms of red phosphorus and magnesium hydroxide in high impact polystyrene. Macromol. Chem. Phys. 205, 2185-2196. http://dx.doi.org/10.1002/macp.200400255.

Braun, U., Balabanovich, A.I., Schartel, B., Knoll, U., Artner, J., Ciesielski, M., Döring, M., Perez, R., Sandler, J.K.W.W., Altstädt, V., Hoffmann, T., Pospiech, D., Do, M., Altsta, V., 2006. Influence of the oxidation state of phosphorus on the decomposition and fire behaviour of flame-retarded epoxy resin composites. Polymer (Guildf). 47, 8495-8508. http://dx.doi.org/10.1016/j.polymer.2006.10.022.

Braun, U., Schartel, B., Fichera, M.A., Jäger, C., Ja, C., Jäger, C., 2007. Flame retardancy mechanisms of aluminium phosphinate in combination with melamine polyphosphate and zinc borate in glass-fibre reinforced polyamide 6,6. Polym. Degrad. Stab. 92, 1528-1545. http://dx.doi.org/10.1016/j.polymdegradstab. 2007.05.007.

Braun, U., Bahr, H., Sturm, H., Schartel, B., 2008. Flame retardancy mechanisms of metal phosphinates and metal phosphinates in combination with melamine cyanurate in glass-fiber reinforced poly(1,4-butylene terephthalate): the influence of metal cation. Polym. Adv. Technol. 19, 680-692. http://dx.doi.org/10.1002/pat.1147.

Brindley, G.W., 1986. Relation between structural disorder and other characteristics of kaolinites and dickites. Clay Clay Miner. 34, 239-249. http://dx.doi.org/10.1346/ CCMN.1986.0340303.

Cabedo, L.L.L.L., Giménez, E., Lagaron, J.M., Gavara, R., Saura, J.J., 2004. Development of EVOH-kaolinite nanocomposites. Polymer (Guildf). 45, 5233-5238. http://dx.doi. org/10.1016/j.polymer.2004.05.018.

Chow, W.S., Ishiaku, U.S., Apostolov, A.A., 2003. The Effect of Organoclay on the Mechanical Properties and Morphology of Injection-Molded Polyamide 6/ Polypropylene Nanocomposites.

Clerc, L., Ferry, L., Leroy, E., Lopez-Cuesta, J.-M.M., 2005. Influence of talc physical properties on the fire retarding behaviour of (ethylene-vinyl acetate copolymer/ magnesium hydroxide/talc) composites. Polym. Degrad. Stab. 88, 504-511. http:// dx.doi.org/10.1016/j.polymdegradstab. 2004.12.010.

Delichatsios, M.A., Zhang, J., 2012. An alternative way for the ignition times for solids with radiation absorption in-depth by simple asymptotic solutions. Fire Mater. 36, 41-47. http://dx.doi.org/10.1002/fam.1084.

Durin-France, A., Ferry, L., Lopez-Cuesta, J.-M.M., Crespy, A., Cuesta, J.L., Lopez Cuesta, J.-M., 2000. Magnesium hydroxide/zinc borate/talc compositions as flame-retardants in EVA copolymer. Polym. Int. 49, 1101-1105. http://dx.doi.org/10.1002/10970126(200010)49:10 < 1101::AID-PI523 > 3.0.CO;2-5.

Fina, A., Feng, J., Cuttica, F., 2013. In-depth radiative heat transmittance through polypropylene/nanoclay composites. Polym. Degrad. Stab. http://dx.doi.org/10.1016/j. polymdegradstab. 2013.02.003.

Giese Jr., R.F., Giese, R.F., 1973. Interlayer bonding in kaolinite, Dickite and Nacrite.
Clays Clay Miner. 21, 145-149. http://dx.doi.org/10.1346/CCMN.1973.0210302.

Hedicke-Höchstötter, K., Lim, G.T., Altstädt, V., 2009. Novel polyamide nanocomposites based on silicate nanotubes of the mineral halloysite. Compos. Sci. Technol. 69, 330-334. http://dx.doi.org/10.1016/j.compscitech.2008.10.011.

Huang, N.H., 2010. Synergistic flame retardant effects between sepiolite and magnesium hydroxide in ethylene-vinyl acetate (EVA) matrix. Express Polym Lett 4, 227-233. http://dx.doi.org/10.3144/expresspolymlett.2010.29.

Kashiwagi, T., Harris, R.H., Zhang, X., Briber, R.M., Cipriano, B.H., Raghavan, S.R., Awad, W.H., Shields, J.R., 2004. Flame retardant mechanism of polyamide 6-clay nanocomposites. Polymer (Guildf). 45, 881-891. http://dx.doi.org/10.1016/j.polymer. 2003.11.036.

Kashiwagi, T., Mu, M., Winey, K., Cipriano, B., Raghavan, S.R., Pack, S., Rafailovich, M., Yang, Y., Grulke, E., Shields, J., Harris, R., Douglas, J., 2008. Relation between the viscoelastic and flammability properties of polymer nanocomposites. Polymer (Guildf). 49, 4358-4368. http://dx.doi.org/10.1016/j.polymer.2008.07.054.

Laachachi, A., Cochez, M., Leroy, E., Ferriol, M., Lopez-Cuesta, J.M., 2007. Fire retardant systems in poly(methyl methacrylate): interactions between metal oxide nanoparticles and phosphinates. Polym. Degrad. Stab. 92, 61-69. http://dx.doi.org/10. 1016/j.polymdegradstab. 2006.09.011.

Laoutid, F., Persenaire, O., Bonnaud, L., Dubois, P., 2013. Flame retardant polypropylene through the joint action of sepiolite and polyamide 6. Polym. Degrad. Stab. 98, 1972-1980. http://dx.doi.org/10.1016/j.polymdegradstab. 2013.07.018.

Leong, Y.W., Bakar, M.B.A., Ishak, Z.A.M., Ariffin, A., Pukanszky, B., Abu Bakar, M.B., 2004. Comparison of the mechanical properties and interfacial interactions between talc, kaolin, and calcium carbonate filled polypropylene composites. J. Appl. Polym. Sci. 91, 3315-3326. http://dx.doi.org/10.1002/app.13542.

Levchik, S.V., Balabanovich, I., Caminob, G., Costab, L., 1996a. Mechanistic study of combustion performance and thermal decomposition behaviour of nylon 6 with added halogen free fire retardants. Polym. Degrad. Stab. 54, 217-222.

Levchik, F., Camino, G., Costa, L., Levchik, S.V., Levchik, G.F., Lesnikovich, A.I., 1996b. Mechanism of action of phsphorous-based flame retardants in nylon 6. III. Ammonium Polyphosphate/Manganese Dioxide. Fire Mater. 20, 183-190. http://dx. doi.org/10.1002/(sici)1099-1018(199607)20:4<183::aid-fam574 > 3.0.co;2-w.

Levchik, G.F., Levchik, S.V., Lesnikovich, A.I., 1996c. Mechanisms of action in flame retardant reinforced nylon 6. Polym. Degrad. Stab. http://dx.doi.org/10.1016/ S0141-3910(96)00063-8.

Levchik, S.V., Balabanovich, A.I., Levchik, G.F., Costa, L., 1997. Effect of melamine and its salts on combustion and thermal decomposition of polyamide 6. Fire Mater. 21, 75-83.

Levchik, S., Weil, E.D., Lewin, M., 1999. Thermal decomposition of aliphatic nylons Polym. Int. 48, 532-557. http://dx.doi.org/10.1002/(SICI)1097-0126(199907) 48:7<532::AID-PI214> 3.0.CO;2-R.

Lyon, R.E., Walters, R.N., 2004. Pyrolysis combustion flow calorimetry. J. Anal. Appl. Pyrolysis 71, 27-46. http://dx.doi.org/10.1016/S0165-2370(03)00096-2.

Lyon, R.E., Walters, R.N.N., Stoliarov, S.I.I., 2007. Screening flame retardants for plastics using microscale combustion calorimetry. Polym. Eng. Sci. 47, 1501-1510. http://dx. doi.org/10.1002/pen.20871.

Norris, A.N., 1990. The mechanical properties of platelet reinforced composites. Int. J. Solids Struct. 26, 663-674.

Paper, S., Biljana, I., Aleksandra, M., Ljiljana, M., 2010. Thermal treatment of kaolin clay to obtain metakaolin. Hem. Ind. 64, 351-356. http://dx.doi.org/10.2298/ HEMIND100322014I.

Pramoda, K., Liu, T., Liu, Z., He, C., Sue, H.-J., 2003. Thermal degradation behavior of polyamide 6/clay nanocomposites. Polym. Degrad. Stab. 81, 47-56. http://dx.doi. org/10.1016/S0141-3910(03)00061-2.

Ptáček, P., Frajkorová, F., Šoukal, F., Opravil, T., 2014. Kinetics and mechanism of three stages of thermal transformation of kaolinite to metakaolinite. Powder Technol. http://dx.doi.org/10.1016/j.powtec.2014.05.047.

Ramani, A., Dahoe, A.E., 2014. On flame retardancy in polycaprolactam composites by aluminium diethylphosphinate and melamine polyphosphate in conjunction with organically modified montmorillonite nanoclay. Polym. Degrad. Stab. 105, 1-11. http://dx.doi.org/10.1016/j.polymdegradstab. 2014.03.020.

Ramani, A., Hagen, M., Hereid, J., 2010. Interaction of a phosphorus-based FR, a nanoclay and PA6. Part 2: interaction of the complete PA6 polymer nanocomposites. Fire 77-93. http://dx.doi.org/10.1002/fam.

Samyn, F., Bourbigot, S., 2012. Thermal decomposition of flame retarded formulations PA6/aluminum phosphinate/melamine polyphosphate/organomodified clay: interactions between the constituents? Polym. Degrad. Stab. 97, 2217-2230. http://dx. doi.org/10.1016/j.polymdegradstab. 2012.08.004.

Sanchez-Olivares, G., Sanchez-Solis, A., Camino, G., Manero, O., 2008. Study on the combustion behavior of high impact polystyrene nanocomposites produced by different extrusion processes. Express Polym Lett 2, 569-578. http://dx.doi.org/10. 3144/expresspolymlett.2008.69.

Schartel, B., Hull, T.R., 2007. Development of fire-retarded materials-interpretation of cone calorimeter data. Fire Mater. 31, 327-354. http://dx.doi.org/10.1002/fam.949.

Schartel, B., Braun, U., Schwarz, U., Reinemann, S., 2003. Fire retardancy of polypropylene/flax blends. Polymer (Guildf). 44, 6241-6250. http://dx.doi.org/10.1016/ S0032-3861(03)00692-X.

Schartel, B., Pawlowski, K.H., Lyon, R.E., 2007. Pyrolysis combustion flow calorimeter: a tool to assess flame retarded PC/ABS materials? Thermochim Acta 462, 1-14. http:// dx.doi.org/10.1016/j.tca.2007.05.021.

Sonnier, R., Ferry, L., Longuet, C., Laoutid, F., Friederich, B., Laachachi, A., Lopez-Cuesta, J.-M., 2011. Combining cone calorimeter and PCFC to determine the mode of action of flame-retardant additives. Polym. Adv. Technol. 22, 1091-1099. http://dx.doi. org/10.1002/pat.1989.

Vahabi, H., Batistella, M., Otazaghine, B., Longuet, C., Ferry, L., Sonnier, R., Lopez- 
Cuesta, J.-M.M., 2012. Influence of a treated kaolinite on the thermal degradation and flame retardancy of poly(methyl methacrylate). Appl. Clay Sci. 70, 58-66. http://dx.doi.org/10.1016/j.clay.2012.09.013.

Vahabi, H., Sonnier, R., Otazaghine, B., Le Saout, G., Lopez-Cuesta, J.M., 2013. Nanocomposites of polypropylene/polyamide 6 blends based on three different nanoclays: thermal stability and flame retardancy. Polimery/Polymers 58, 350-360. http://dx.doi.org/10.14314/polimery.2013.350.

Weil, E.D., Levchik, S., 2004. Current practice and recent commercial developments in flame retardancy of polyamides. J. Fire Sci. 22, 251-264. http://dx.doi.org/10.1177/
0734904104040546

Zhan, Z., Xu, M., Li, B., 2015. Synergistic effects of sepiolite on the flame retardant properties and thermal degradation behaviors of polyamide 66/aluminum diethylphosphinate composites. Polym. Degrad. Stab. 117, 66-74. http://dx.doi.org/10. 1016/j.polymdegradstab. 2015.03.018.

Zhang, Y., Hu, Y., Song, L., Wu, J., Fang, S., 2008. Influence of Fe-MMT on the Fire Retarding Behavior and Mechanical Property of (Ethylene-Vinyl Acetate Copolymer/ Magnesium Hydroxide) Composite. pp. 960-966. http://dx.doi.org/10.1002/pat. 